This item was submitted to Loughborough's Research Repository by the author.

Items in Figshare are protected by copyright, with all rights reserved, unless otherwise indicated.

\title{
In situ modification of chromatography adsorbents using cold atmospheric pressure plasmas
}

\section{PLEASE CITE THE PUBLISHED VERSION}

http://dx.doi.org/10.1063/1.4807391

\section{PUBLISHER}

(c) American Institute of Physics

VERSION

VoR (Version of Record)

\section{LICENCE}

CC BY-NC-ND 4.0

\section{REPOSITORY RECORD}

Olszewski, P., Thomas C. Willett, Eirini Theodosiou, Owen R.T. Thomas, and James L. Walsh. 2015. "In Situ Modification of Chromatography Adsorbents Using Cold Atmospheric Pressure Plasmas". figshare. https://hdl.handle.net/2134/18130. 


\section{AIP Apoled Phosics \\ Letters}

In situ modification of chromatography adsorbents using cold atmospheric pressure plasmas

P. Olszewski, T. C. Willett, E. Theodosiou, O. R. T. Thomas, and J. L. Walsh

Citation: Applied Physics Letters 102, 204104 (2013); doi: 10.1063/1.4807391

View online: http://dx.doi.org/10.1063/1.4807391

View Table of Contents: http://scitation.aip.org/content/aip/journal/apl/102/20?ver=pdfcov

Published by the AIP Publishing

\section{Articles you may be interested in}

Modeling the construction of polymeric adsorbent media: Effects of counter-ions on ligand immobilization and pore structure

J. Chem. Phys. 140, 084901 (2014); 10.1063/1.4865910

Assessment of the roles of various inactivation agents in an argon-based direct current atmospheric pressure cold plasma jet

J. Appl. Phys. 111, 123305 (2012); 10.1063/1.4730627

Optofluidic in situ maskless lithography of charge selective nanoporous hydrogel for DNA preconcentration

Biomicrofluidics 4, 043014 (2010); 10.1063/1.3516037

A molecular dynamics study on the transport of a charged biomolecule in a polymeric adsorbent medium and its adsorption onto a charged ligand

J. Chem. Phys. 133, 084904 (2010); 10.1063/1.3473930

Electrical detection of biomaterials using $\mathrm{AIGaN} / \mathrm{GaN}$ high electron mobility transistors

J. Appl. Phys. 104, 031101 (2008); 10.1063/1.2959429

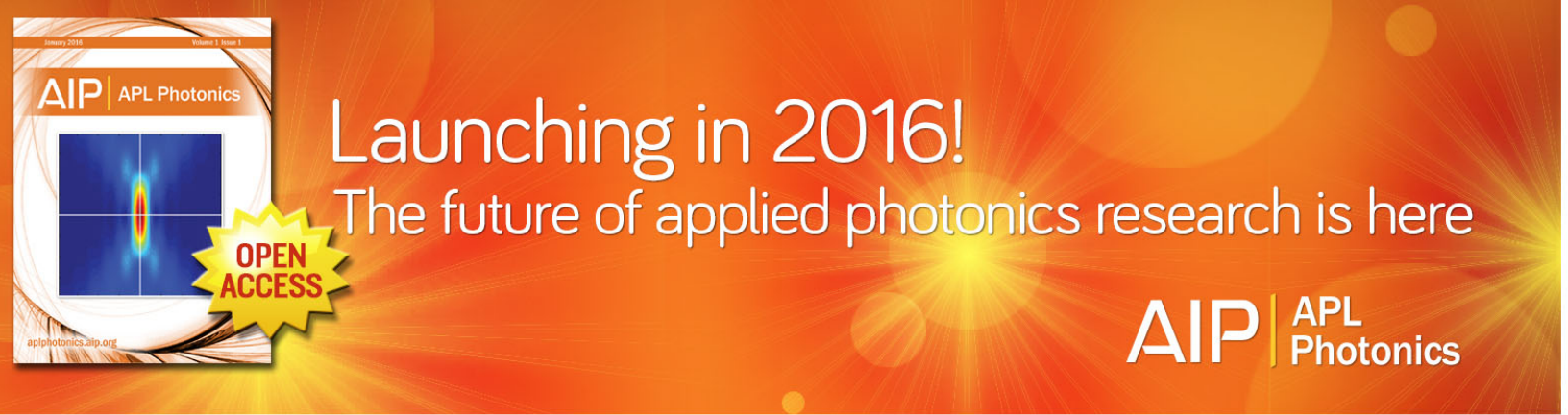




\title{
In situ modification of chromatography adsorbents using cold atmospheric pressure plasmas
}

\author{
P. Olszewski, ${ }^{1, a)}$ T. C. Willett, ${ }^{2, a)}$ E. Theodosiou, ${ }^{3}$ O. R. T. Thomas, ${ }^{2, b)}$ and J. L. Walsh ${ }^{1, b)}$ \\ ${ }^{1}$ Department of Electrical Engineering and Electronics, University of Liverpool, Liverpool, \\ Merseyside L69 3GJ, United Kingdom \\ ${ }^{2}$ School of Chemical Engineering, College of Engineering and Physical Sciences, \\ University of Birmingham, Edgbaston, Birmingham B15 2TT, United Kingdom \\ ${ }^{3}$ Department of Chemical Engineering, School of Aeronautical, Automotive, Chemical and Materials \\ Engineering, Loughborough University, Loughborough, Leicestershire, LE11 3TU, United Kingdom
}

(Received 23 April 2013; accepted 4 May 2013; published online 24 May 2013)

\begin{abstract}
Efficient manufacturing of increasingly sophisticated biopharmaceuticals requires the development of new breeds of chromatographic materials featuring two or more layers, with each layer affording different functions. This letter reports the in situ modification of a commercial beaded anion exchange adsorbent using atmospheric pressure plasma generated within gas bubbles. The results show that exposure to $\mathrm{He}-\mathrm{O}_{2}$ plasma in this way yields significant reductions in the surface binding of plasmid DNA to the adsorbent exterior, with minimal loss of core protein binding capacity; thus, a bi-layered chromatography material exhibiting both size excluding and anion exchange functionalities within the same bead is produced. (C) 2013 AIP Publishing LLC. [http://dx.doi.org/10.1063/1.4807391]
\end{abstract}

Preparative chromatography, a core technology within the biopharma industry for several decades, plays pivotal roles in the downstream processing (i.e., recovery and purification operations) of modern biopharmaceuticals, ${ }^{1-3}$ but is increasingly being viewed as a serious bottleneck in manufacturing. ${ }^{3,4}$ This is largely because the development of chromatographic hardware and especially media has not kept pace with biological innovations upstream, i.e., rocketing product titers, increasing size, and complexity of emerging bio-products. ${ }^{3,4}$ Modern chromatography media are infinitely superior to their ancestors from the mid $1950 \mathrm{~s},{ }^{1}$ but in stark contrast to the monumental changes observed in bio-product development over the same period, the basic design ("monofunctional porous polymeric beads"; Fig. 1(a) remains effectively unchanged. ${ }^{5}$ As a result, few commercially available chromatographic materials tailored to the separation of many newer increasingly complex products exist at the present time. This point is beautifully highlighted by the unique separation challenges posed by "biological nanoplexes," a rapidly growing and diverse product grouping characterized by large physical size, fragility, complex surfaces "plus" chemical similarity to smaller contaminating macromolecular components. ${ }^{5}$ These properties prohibit the efficient manufacture of nanoplexes using routes and chromatographic materials established for therapeutic human proteins of much smaller dimensions. ${ }^{6-8}$ For example, whilst ion exchange chromatography is extensively used for the commercial scale purification of antibiotics and protein-based drugs, its application for biological nanoplexes (e.g., naked plasmid DNA, viral vectors, virus-like particles, mega-molecular vaccines, megaprotein complexes, IgMs) is far less attractive. This is because these species are often as large as, or larger than, the pores of most conventional chromatographic media; thus

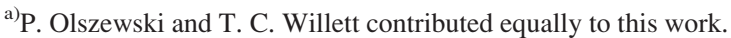

${ }^{b)}$ Authors to whom correspondence should be addressed. Electronic addresses: o.r.t.thomas@bham.ac.uk and jlwalsh@liv.ac.uk
}

their adsorption is confined to the exterior surface of the adsorbent, resulting in exceptionally low target binding capacities per unit volume. ${ }^{8-11}$

New types of beaded chromatography adsorbents featuring two or more distinct functional regions spatially separated from one another within the same support bead have been the subject of a handful of research reports since $2002 ;^{5,12-17}$ the most promising of these describing the manufacture and testing of bi-layered bi-functional supports comprising ion exchange (IEC) functionalized cores surmounted by outer size excluding (SEC) layers. ${ }^{5,13-15}$ The main attraction of the bi-layered SEC-IEC support architecture (Fig. 1(b)) is that it enables efficient separation of certain nanoplex bio-products (e.g., plasmid DNA) from smaller, but chemically very similar "problem" contaminants (protein, RNA) in a "one column—one bead" chromatography process combining size exclusion and ion exchange principles. $^{5,13,14}$ The ideal bi-layered SEC-IEC support should possess inert mechanically reliable "non-stick" exteriors or barriers, that are freely accessible to smaller components (proteins, RNA), but not larger entities, such as long chain nucleic acids, cell debris fragments, nanoplexes, etc., and in order not to compromise mass transport and sorption properties, they must also be very thin, i.e., ideally $<1 \mu \mathrm{m}$. ${ }^{5,18}$ To date, these criteria have not been met.

This letter details the in situ generation of atmospheric pressure plasma within an aqueous solution of "soft" porous hydrogel chromatography adsorbents; the reactive oxygen species (ROS) produced in the plasma are transported to the chromatography beads via gas bubbles and are shown to effectively remove surface functionality while leaving core functionality intact. Given that the technique is applied in $s i t u$, it significantly expands the range of chromatography materials that can be modified to exhibit both size exclusion and the specific adsorptive properties, i.e., ion exchange, hydrophobic interaction, mixed mode, or affinity adsorption. 

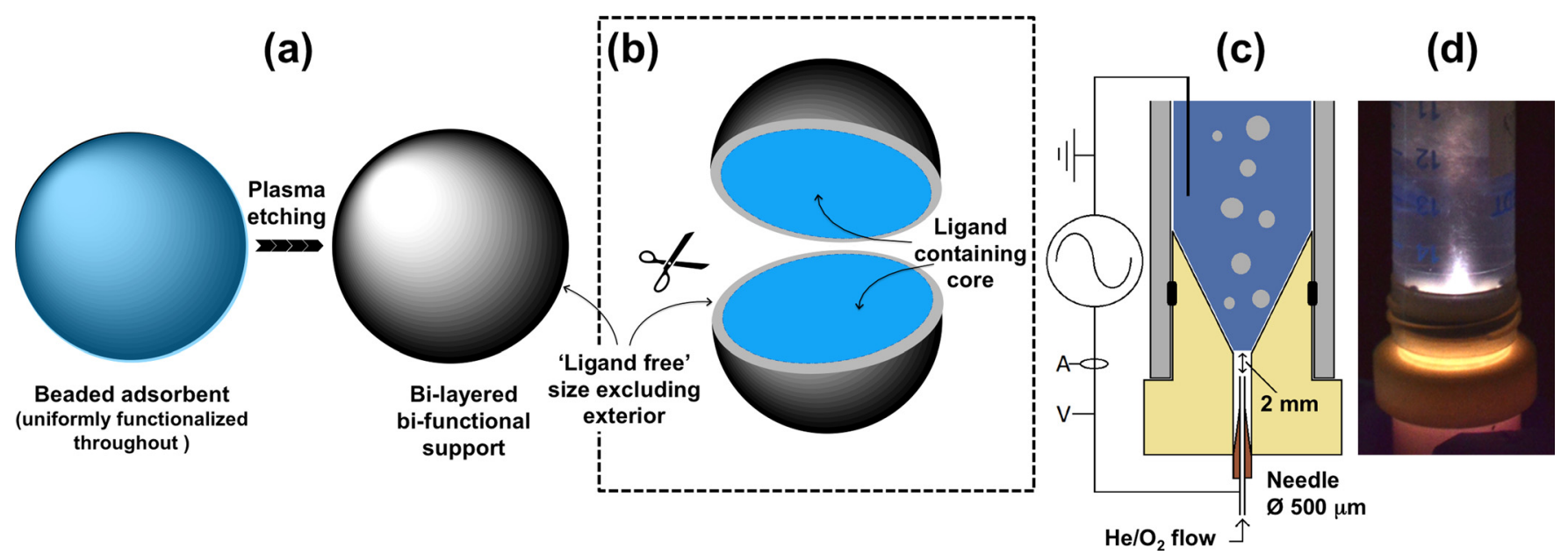

FIG. 1. Schematics illustrating (a) plasma surface etching of a chromatography adsorbent bead to form a bi-layered bi-functional support, (b) sectioning of through the resulting support to highlight the "ligand free" exterior and ligand functionalized core, (c) the underwater fluidized bed plasma treatment reactor operating with $\mathrm{He}-\mathrm{O}_{2}$ at an input power of $3.7 \mathrm{~W}$. Also shown is a photograph (d) of the plasma reactor in operation.

Figures 1(c) and 1(d) show the reactor design used for the treatment of aqueous slurries of support; it consisted of a ceramic base through which a hollow needle of $500 \mu \mathrm{m}$ diameter was inserted. The sides of the ceramic base are intentionally sloped to encourage the transport of support particles toward the plasma region. A gas flow was directed through the needle at a rate of 0.05 Standard Liters per Minute (SLM), the gas composition used was either oxygen $\left(\mathrm{O}_{2}\right)$ or helium $(\mathrm{He})$ with $0.5 \% \mathrm{O}_{2}$ admixture. The output of a high voltage sinusoidal power source, operating at $14.5 \mathrm{kHz}$, was connected to the hollow needle and a ground electrode placed within the aqueous support slurry. In order to access optical information from the plasma, a second reactor was fabricated employing a quartz housing, thus facilitating the transmission of UV; all critical dimensions (i.e., needle diameter, distance between needle and liquid) in the second reactor matched those in the actual treatment reactor. Slurries of the strong anion exchange chromatography adsorbent, Q Sepharose Fast Flow (GE Healthcare, Sweden), were prepared (total volume $8 \mathrm{ml}$, settled bed concentrations of $12.5 \%$ $\mathrm{v} / \mathrm{v}$ and $25 \% \mathrm{v} / \mathrm{v}$ with respect to total slurry volume) in $15 \mathrm{ml}$ plastic centrifuge tubes and attached to the ceramic base of the reactor. Following attachment of the ceramic base and inversion of the centrifuge tube, a $1 \mathrm{~cm} \varnothing$ hole was made in the tip of the tube to allow for a ground electrode to be inserted and act as a means for gas to escape. This porous beaded matrix, comprising a cross-linked $6 \%$ agarose backbone derivatized throughout with the strong quaternary ammonium (Q) anion exchange group, was selected as representative of the majority of soft hydrogel based commercial chromatographic adsorbents employed for low pressure chromatographic separation of biomacromolecules, such as globular proteins. In these polymeric media, the high water content (typically $>90 \%$ of the support volume), renders them-in stark contrast to rarer rigid types able withstand prolonged vacuum conditions ${ }^{2,5}$ (e.g., gel-in-a-shell' or controlled pore glass supports) — poorly suited to vacuum plasma processing.

The selectivity of "surface vs. core" modification following plasma treatment of Q Sepharose Fast Flow was evaluated in simple batch binding tests, conducted in $0.05 \mathrm{M}$ Tris- $\mathrm{HCl}$
pH 7.5 with two differently sized negatively charged macromolecular binding probes; i.e., a $27.4 \mathrm{kbp}$ supercoiled plasmid DNA (pDNA) much larger than the adsorbent's pores (binding strictly limited to the exterior surface of the adsorbent), ${ }^{8-11}$ and one small enough to access most of the interior pores, the $66.4 \mathrm{kDa}$ globular protein, bovine serum albumin (BSA). Equilibrated adsorbent samples $(25 \mu \mathrm{l})$ were mixed with $1 \mathrm{ml}$ portions of either $25 \mu \mathrm{g} / \mathrm{ml}$ pDNA or $10 \mathrm{mg} / \mathrm{ml} \mathrm{BSA}$. After $0.5 \mathrm{~h}$ at room temperature, the adsorbents were recovered by centrifugation in a microfuge before carefully aspirating the supernatants and assaying for residual pDNA or BSA content as described previously. ${ }^{5}$ The results of static pDNA and BSA binding studies are shown in Fig. 2 for adsorbents treated with $\mathrm{He}-\mathrm{O}_{2}$ and $\mathrm{O}_{2}$ plasma over various time periods and average plasma input powers. Significant losses in "surface" pDNA binding with much lower reductions in "core" BSA binding were observed for all $3.7 \mathrm{~W}$ He- $\mathrm{O}_{2}$ plasma treated samples. The optimum conditions were observed using the shortest treatment time of $150 \mathrm{~s}$, which resulted in a $>67 \%$ reduction in "surface" pDNA binding with just $8 \%$ loss of core BSA binding capacity. Longer $\mathrm{He}-\mathrm{O}_{2}$ plasma treatment times (300 or $600 \mathrm{~s})$ proved detrimental to the selectivity of "surface vs. core" modification. Though the reduction in surface pDNA binding increased to over 70\%, the loss of core BSA binding rose significantly, reaching nearly $14 \%$ after $600 \mathrm{~s}$ of contact. Very similar results were obtained for $\mathrm{He}-\mathrm{O}_{2}$ treatment of two diethylaminoethyl (DEAE) functionalized anion exchange chromatographic media, EMD Fractogel DEAE and DEAE Sepharose Fast Flow adsorbents (data not shown). The mass transfer of various ROS species can be used to explain the above findings. Several studies have demonstrated that plasma generated ROS within bubbles are transferred to the liquid phase ${ }^{19,20}$ however, the penetration depths of highly reactive species such $\mathrm{O}, \mathrm{O}^{*}$, and $\mathrm{OH}$ are limited $(<10 \mu \mathrm{m})$, hence they are only able to interact with the exteriors of adsorbent particles $(\sim 90 \mu$ m mean $\varnothing)$ coming into close contact with the plasma bubble-liquid interface. The concentration of longer lived species, especially $\mathrm{H}_{2} \mathrm{O}_{2}$, increase steadily over time, ${ }^{19}$ with the potential to interact with both the surface and core of the adsorbent particles; this finding goes someway to explaining the increased loss of core binding observed at longer 


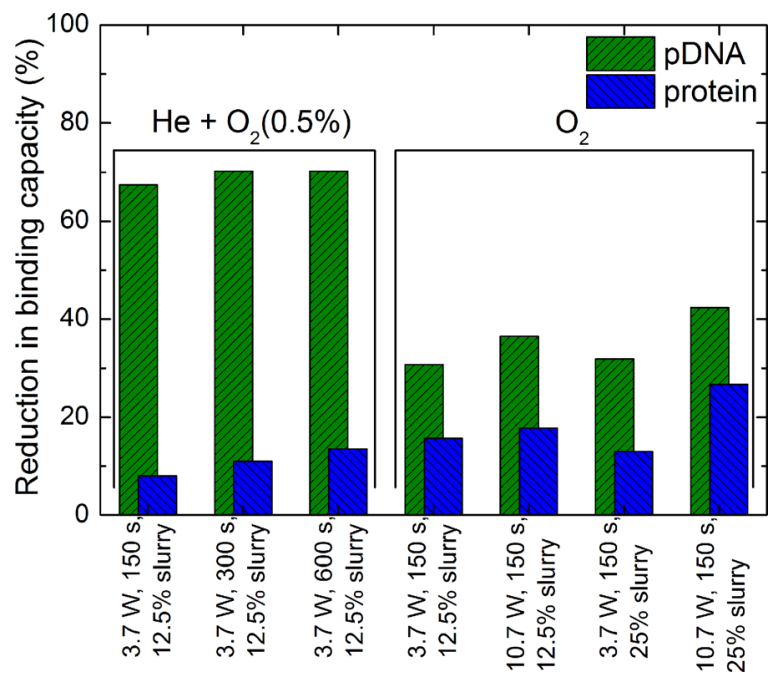

FIG. 2. Effect of $\mathrm{He}-\mathrm{O}_{2}$ and $\mathrm{O}_{2}$ underwater plasma treatments on reductions of "surface" pDNA (green hatched bars) and "core" BSA (blue hatched bars) binding capacity of Q Sepharose FF.

treatment times. Interestingly, the results obtained for $\mathrm{O}_{2}$ plasma treatments differ significantly from those obtained using a $\mathrm{He}-\mathrm{O}_{2}$ discharge (Fig. 2). In contrast to $\mathrm{He}-\mathrm{O}_{2}$ plasma treatment, the losses in pDNA $(31 \%-42 \%)$ and BSA (15\%-27\%) binding indicated comparatively poor "surface" over "core" modification selectivity for the $\mathrm{O}_{2}$ plasma.

The differences observed between $\mathrm{He}-\mathrm{O}_{2}$ and $\mathrm{O}_{2}$ plasma treatments were not initially consistent with expectation, plasmas generated in either gas mixture are well known to produce an abundance of ROS including $\mathrm{OH}, \mathrm{O}, \mathrm{O}^{*},{ }^{1} \mathrm{O}_{2}$, $\mathrm{O}_{3}, \mathrm{H}_{2} \mathrm{O}_{2}$, and $\mathrm{O}_{2}{ }^{-19,21}$ Figure 3 highlights the emission

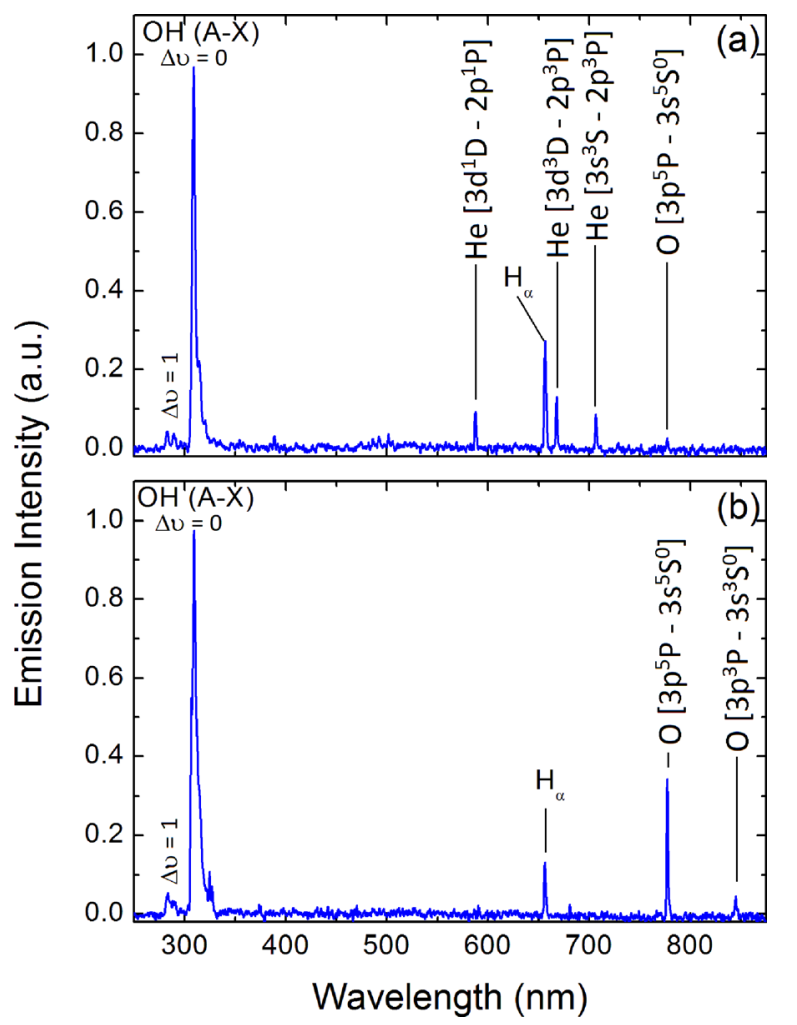

FIG. 3. Low resolution emission spectra from 250-850 nm showing: (a) excited states in a $3.7 \mathrm{~W}$ He- $\mathrm{O}_{2}$ plasma discharge; and (b) excited states in a $3.7 \mathrm{~W} \mathrm{O}_{2}$ plasma discharge. spectra from $\mathrm{He}-\mathrm{O}_{2}$ and $\mathrm{O}_{2}$ plasmas; both are clearly dominated by the $\mathrm{OH}\left(\mathrm{A}^{2} \Sigma-\mathrm{X}^{2} \Pi\right)$ emission. In both cases, the main production pathway for $\mathrm{OH}(\mathrm{A})$ is through the dissociative electron excitation of water; with an additional pathway in the $\mathrm{He}-\mathrm{O}_{2}$ discharge of the dissociative excitation of water with metastable $\mathrm{He}(19.8 \mathrm{eV}) .^{22,23}$ Notably, the $\mathrm{O}_{2}$ discharge indicates a strong emission from $\mathrm{O}^{*}$ at $777 \mathrm{~nm}\left({ }^{5} \mathrm{P} \rightarrow{ }^{5} \mathrm{~S}^{0}\right)$ and $844 \mathrm{~nm}\left({ }^{3} \mathrm{P} \rightarrow{ }^{3} \mathrm{~S}^{0}\right)$, suggesting increased production of the powerful oxidant $\mathrm{O}^{*}$. While optical emission spectroscopy does not provide a clear indication of ground state species, it is safe to assume that both discharges are capable of producing a plethora of oxidizing species, thus the observed differences in adsorbent modification are not explained by a lack of ROS production.

To further probe the differences between the $\mathrm{He}-\mathrm{O}_{2}$ and $\mathrm{O}_{2}$ discharges, Fig. 4 shows high-resolution optical emission spectra of the $\mathrm{OH}\left(\mathrm{A}^{2} \Sigma-\mathrm{X}^{2} \Pi, \Delta v=0\right)$ transition for both discharges operating at $3.7 \mathrm{~W}$; by fitting the experimental data with a synthetic spectra calculated at a known temperature, the rotational temperature is ascertained. It is well known that a deviation from a Boltzmann rotational population distribution occurs due to the formation process of $\mathrm{OH}(\mathrm{A})$; hence a two-temperature fitting routine has been adopted, similar to that used by Bruggeman et al. ${ }^{24}$ As the rotational relaxation time is fast at atmospheric pressure, the temperature $T_{1}$ from the two-temperature fitting routine can be considered as a reliable estimate of gas temperature. ${ }^{23}$ The best-fit temperature, $\mathrm{T}_{1}$, in the $\mathrm{He}-\mathrm{O}_{2}$ discharge was

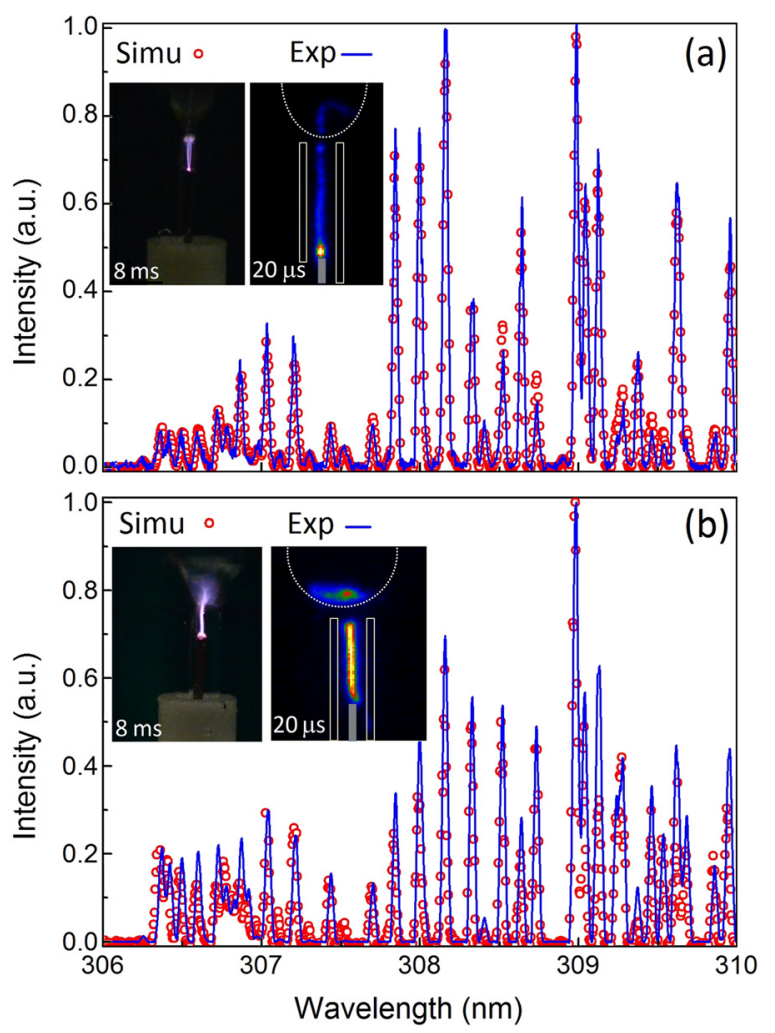

FIG. 4. High resolution emission spectra from 306 to $310 \mathrm{~nm}$ showing $\mathrm{OH}(\mathrm{A}-\mathrm{X})$ emission in: (a) $\mathrm{He}-\mathrm{O}_{2}$ plasma at $3.7 \mathrm{~W}$, best-fit parameters $\mathrm{T}_{1}=380 \mathrm{~K}(90 \%)$ and $\mathrm{T}_{2}=6500 \mathrm{~K}(10 \%)$; and (b) $\mathrm{O}_{2}$ plasma operating at $3.7 \mathrm{~W}$, best-fit parameters $\mathrm{T}_{1}=1100 \mathrm{~K}(80 \%)$ and $\mathrm{T}_{2}=4000 \mathrm{~K}(20 \%)$. The solid blue lines indicate the experimental data, the red circles represent bestfit theoretical spectra, and the inserts show images captured using exposure times of $8 \mathrm{~ms}$ and $20 \mu \mathrm{s}$, respectively. 
found to be $380 \pm 50 \mathrm{~K}$; in contrast, the best-fit temperature in the $\mathrm{O}_{2}$ discharge was significantly higher at $1100 \pm 50 \mathrm{~K}$. Such discrepancies are typical and are linked to the thermal conductivities of atomic and molecular gases and differing energy transfer mechanisms. ${ }^{23}$ Also shown in Fig. 4 are images taken with $8 \mathrm{~ms}$ and $20 \mu$ s exposure times, thus capturing $\sim 200$ discharge events and $\sim 1$ discharge event, respectively. In both cases, it is clear that a filamentary discharge is produced; this is consistent with the previous studies of plasma generation in bubbles. ${ }^{24,25}$ Crucially, in $\mathrm{O}_{2}$, an intense filament was observed to extend directly from the pin electrode to the bubble (or liquid surface after bubble detachment). Given that temperatures in excess of $1000 \mathrm{~K}$ are expected, it is highly likely that adsorbent material passing in close proximity to the discharge will experience significant heating, with the potential to cause structural damage. In the $\mathrm{He}-\mathrm{O}_{2}$ case, a filamentary discharge is also observed. However, the peak emission intensity arises at the electrode tip some $2 \mathrm{~mm}$ from the capillary exit. As the temperature measurements are not spatially resolved, it is likely that this intense region dominates the $\mathrm{OH}$ emission profile and the plasma reaching the bubble has a significantly lower temperature than the $380 \mathrm{~K}$ measured.

Analysis of electrical data, shown in Fig. 5, indicates that the peak dissipated power in each discharge differed significantly despite the time-averaged power being held constant. In $\mathrm{He}-\mathrm{O}_{2}$ current, spikes of $8-10 \mathrm{~mA}$ were observed in each half-cycle of the applied voltage, resulting in peak instantaneous dissipated powers of $\sim 15 \mathrm{~W}$. Conversely, in $\mathrm{O}_{2}$ a large and sporadic discharge current spike was observed roughly once in every 10 applied voltage cycles, with amplitudes between 100 and $200 \mathrm{~mA}$, leading to instantaneous peak powers of several kilowatts. Increasing the time-averaged

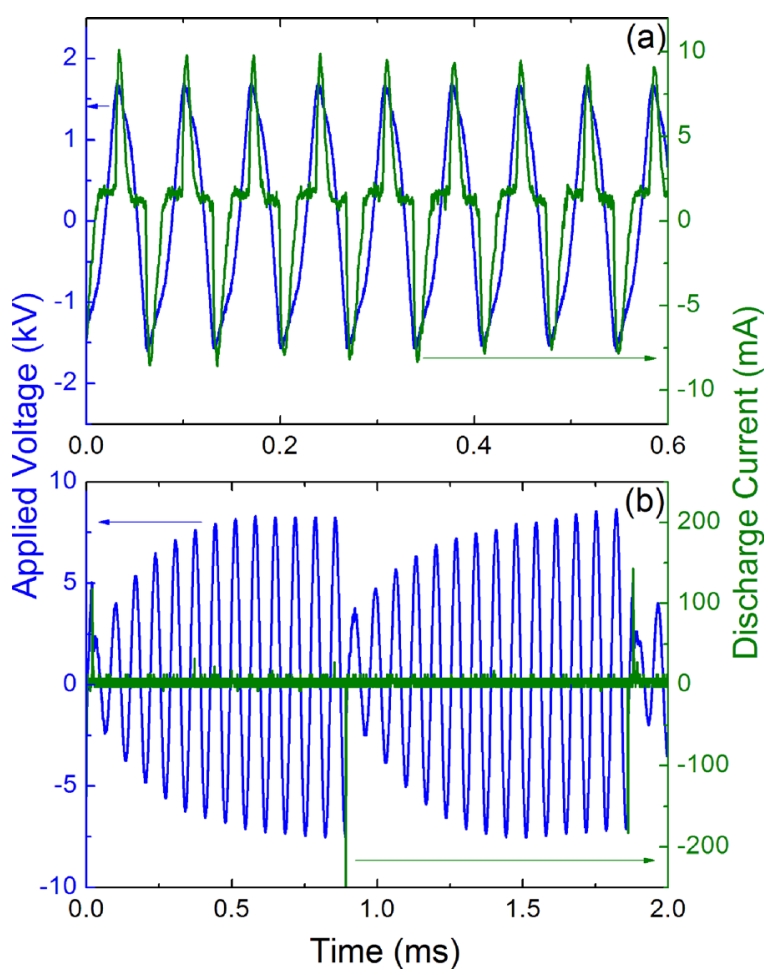

FIG. 5. Current and voltage waveforms in: (a) a $\mathrm{He}-\mathrm{O}_{2}$ discharge operated at $3.7 \mathrm{~W}$; and (b) an $\mathrm{O}_{2}$ discharge operated at $3.7 \mathrm{~W}$. input power in the $\mathrm{O}_{2}$ discharge from $3.7 \mathrm{~W}$ to $10.7 \mathrm{~W}$ yielded an increase in the number of discharge events in a given time period to approximately once in every three applied voltage cycles. The differences between the $\mathrm{He}-\mathrm{O}_{2}$ and $\mathrm{O}_{2}$ discharge current waveforms are attributed to the different physical characteristics of each plasma, most notably the electron density and breakdown voltage, which are both significantly higher in $\mathrm{O}_{2}$.

In order to assess the impact of plasma treatment on the structural integrity of the adsorbent material, scanning electron microscopy (SEM) was employed. After plasma treatment, samples were prepared by dehydrating in ethanol followed by critical point drying. Figure 6 shows SEM images of untreated and $\mathrm{He}-\mathrm{O}_{2}$ and $\mathrm{O}_{2}$ plasma treated Q Sepharose Fast Flow media. The appearance of Q Sepharose Fast Flow remained unaffected following treatment with He$\mathrm{O}_{2}$ plasma (compare Figs. 6(a) and 6(b)). In stark contrast, numerous deep punctures or holes (ranging from 5 to $25 \mu \mathrm{m}$ across) are clearly evident in adsorbent particles previously exposed to the $\mathrm{O}_{2}$ plasma (Fig. 6(c)). Such damage is a likely result of individual supports coming in direct contact with an
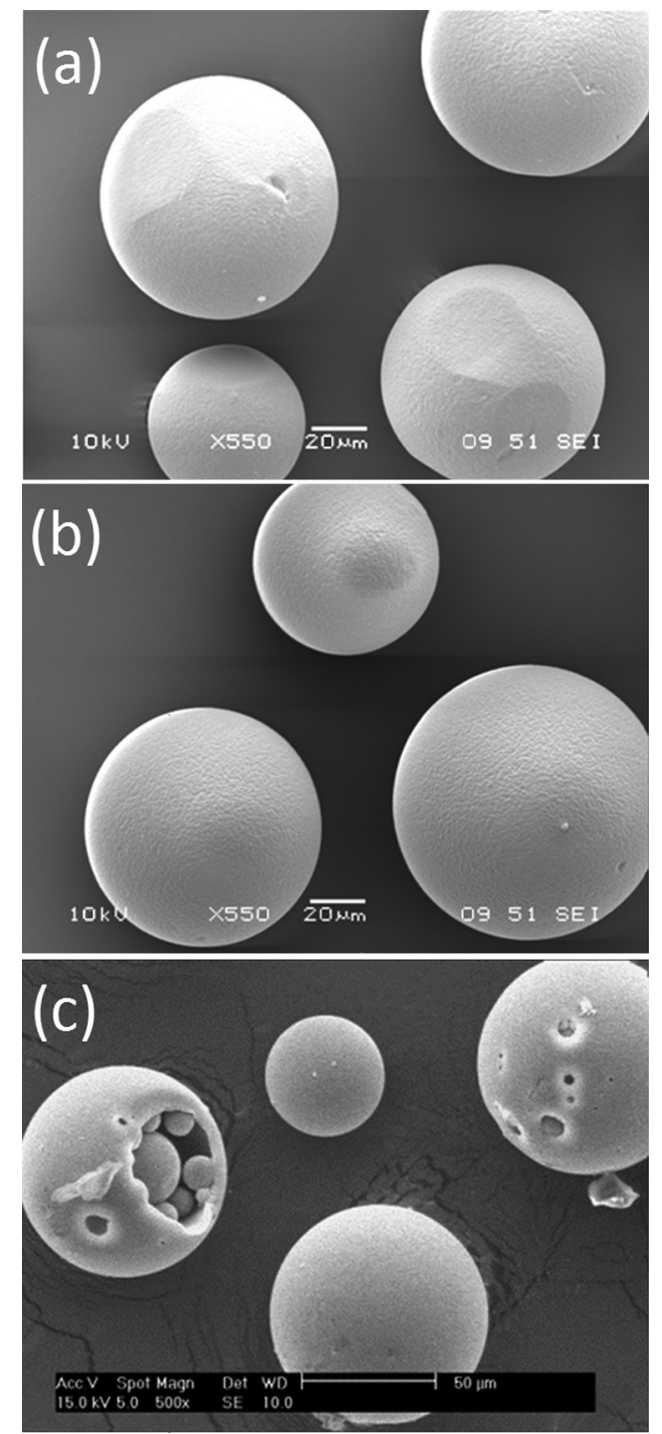

FIG. 6. SEM images of (a) untreated Q Sepharose Fast Flow and Q Sepharose Fast Flow following $150 \mathrm{~s}$ of exposure to $3.7 \mathrm{~W} \mathrm{He}-\mathrm{O}_{2}$ (b), and $\mathrm{O}_{2}$ (c) plasmas. 
intensely hot plasma filament. The punctures not only increase the amount of surface that pDNA can access and bind to, they also simultaneously reduce the overall core volume of individual adsorbent beads and therefore their BSA binding capacity. The severe damage noted here clearly precludes the use of $\mathrm{O}_{2}$ plasma for surface etching of soft chromatography materials, and also fully explains the lack of surface vs. core modification selectivity inferred from the static pDNA and BSA binding studies (see Fig. 2).

In summary, this letter reports a technique to modify the surface properties of chromatography adsorbent media directly in aqueous solution. The results show a promising level of selectivity can be achieved between surface pDNA binding and core protein binding, thus forming a bifunctional media and potentially addressing one of the critical bottlenecks associated with packed bed chromatography. Moreover, the work represents one of the first demonstrations of atmospheric pressure plasma processing of materials directly in solution; it is envisaged that the techniques detailed will have considerable application potential not just in the field of packed bed chromatography, but across the whole field of plasma surface engineering.

This work is funded by the Biotechnology and Biological Sciences Research Council/Bioprocessing Research Industry Club (BRIC) programme (Grant No. BB/F004982/1), and the Engineering and Physical Sciences Research Council (Grant No. EP/J005894/1).

${ }^{1}$ J.-C. Janson and P. Hedman, Adv. Biochem. Eng. 25, 43 (1982).

${ }^{2} \mathrm{E}$. Boschetti and J. Coffmann, Bioseparation and Bioprocessing, edited by G. Subramanian (Wiley-VCH Press, Weinheim, Germany, 1998), p. 157, Vol. 1.

${ }^{3}$ T. M. Przybycien, N. S. Pujar, and L. M. Steele, Curr. Opin. Biotechnol. 15, 469 (2004).
${ }^{4}$ L. Giovannoni, M. Ventani, and U. Gottschalk, BioPharm Int. 21, 48 (Dec 2008).

${ }^{5}$ A. Arpanaei, B. Winther-Jensen, E. Theodosiou, P. Kingshott, T. J. Hobley, and O. R. T. Thomas, J. Chromatogr. A 1217, 6905 (2010).

${ }^{6}$ D. M. F. Prazeres, G. N. M. Ferreira, G. A. Monteiro, C. L. Cooney, and J. M. S. Cabral, Trends Biotechnol. 17, 169 (1999).

${ }^{7}$ G. N. M. Ferreira, G. A. Monteiro, D. M. F. Prazeres, and J. M. S. Cabral, Trends Biotechnol. 18, 380 (2000).

${ }^{8}$ M. S. Levy, I. J. Collins, J. T. Tsai, P. Ayazi Shamlou, J. M. Ward, and P. Dunnill, Trends Biotechnol. 18, 296 (2000).

${ }^{9}$ I. Theodossiou, M. Søndergaard, and O. R. T. Thomas, Bioseparation 10, 31 (2001).

${ }^{10}$ D. M. F. Prazeres, T. Schluep, and C. L. Cooney, J. Chromatogr. A 806, 31 (1998).

${ }^{11}$ A. Ljunglöf, P. Bergvall, R. Bhikhabhai, and R. Hjorth, J. Chromatogr. A 844, 129 (1999).

${ }^{12}$ M. B. Dainiak, I. Y. Galaev, and B. Mattiasson, J. Chromatogr. A 942, 123 (2002).

${ }^{13}$ P.-E. Gustavsson, R. Lemmens, T. Nyhammar, P. Busson, and P.-O. Larsson, J. Chromatogr. A 1038, 131 (2004).

${ }^{14}$ C. Kepka, R. Lemmens, J. Vasi, T. Nyhammar, and P.-E. Gustavsson, J. Chromatogr. A 1057, 115 (2004).

${ }^{15}$ M. E. Viloria-Cols, R. Hatti-Kaul, and B. Mattiasson, J. Chromatogr. A 1043, 195 (2004).

${ }^{16}$ M. B. Dainiak, I. Y. Galaev, and B. Mattiasson, Biotechnol. Prog. 18, 815 (2002).

${ }^{17}$ M. Jahanshahi, L. Partida-Martinez, and S. Hajizadeh, J. Chromatogr. A 1203, 13 (2008).

${ }^{18}$ I. Theodossiou and O. R. T. Thomas, J. Chromatogr. A 971, 73 (2002).

${ }^{19}$ N. Takeuchi, Y. Ishii, and K. Yasuoka, Plasma Sources Sci. Technol. 21, 015006 (2012).

${ }^{20}$ D. X. Liu, C. Chen, A. J. Yang, M. Z. Rong, F. Iza, and M. G. Kong, in Abstracts IEEE International Conference on Plasma Science (ICOPS), 8-13 July 2012.

${ }^{21}$ D. X. Liu, F. Iza, X. H. Wang, M. G. Kong, and M. Z. Rong, Appl. Phys. Lett. 98, 221501 (2011)

${ }^{22}$ P. Bruggeman, J. Degroote, J. Vierendeels, and C. Leys, Plasma Sources Sci. Technol. 17, 025008 (2008).

${ }^{23}$ T. Verreycken, D. C. Schram, C. Leys, and P. Bruggeman, Plasma Sources Sci. Technol. 19, 045004 (2010).

${ }^{24}$ P. Bruggeman, T. Verreycken, M. A. Gonzalez, J. L. Walsh, M. G. Kong, C. Leys, and D. C. Schram, J. Phys. D: Appl. Phys. 43, 124005 (2010).

${ }^{25} \mathrm{~K}$. Tachibana, Y. Takekata, Y. Mizumoto, H. Motomura, and M. Jinno, Plasma Sources Sci. Technol. 20, 034005 (2011). 